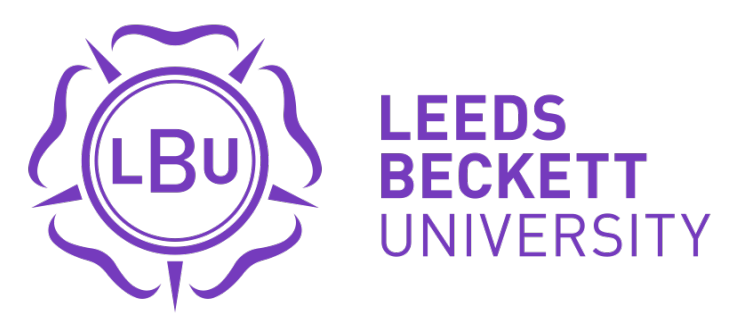

Citation:

Sparkes, A (2020) Autoethnography : Accept, revise, reject? Reflections of an evaluative self. Qualitative Research in Sport, Exercise and Health, 12 (2). pp. 289-302. ISSN 1939-845X DOI: https://doi.org/10.1080/2159676X.2020.1732453

Link to Leeds Beckett Repository record:

https://eprints.leedsbeckett.ac.uk/id/eprint/6619/

Document Version:

Article (Accepted Version)

This is an Accepted Manuscript of an article published by Taylor \& Francis in 'Qualitative Research in Sport, Exercise and Health' on 5th March 2020, available online: https://www.tandfonline.com/doi/full/10.1080/2159676X.2020.1732453

The aim of the Leeds Beckett Repository is to provide open access to our research, as required by funder policies and permitted by publishers and copyright law.

The Leeds Beckett repository holds a wide range of publications, each of which has been checked for copyright and the relevant embargo period has been applied by the Research Services team.

We operate on a standard take-down policy. If you are the author or publisher of an output and you would like it removed from the repository, please contact us and we will investigate on a case-by-case basis.

Each thesis in the repository has been cleared where necessary by the author for third party copyright. If you would like a thesis to be removed from the repository or believe there is an issue with copyright, please contact us on openaccess@leedsbeckett.ac.uk and we will investigate on a case-by-case basis. 
Autoethnography: Accept, revise, reject? Reflections of an evaluative self

Accepted version published in Qualitative Research in Sport, Exercise and Heath, 2020, Volume 12, Number 2, pages 289-302

Andrew C. Sparkes

Carnegie School of Sport

Leeds Beckett University

Fairfax Hall, Room 124

Headingly Campus

Leeds

LS6 3QS

a.c.sparkes@leedsbeckett.ac.uk 


\section{Autoethnography: Accept, revise, reject? An evaluative self reflects}

\section{Abstract}

In this article I offer some reflections of how my evaluative self goes about passing judgment on different kinds of autoethnography. I begin by making distinctions between the autobiographical and the autoethnographic before raising questions about whether or not self-reflexive accounts of the fieldwork process can claim the title of autoethnography. Following this, I consider the lists of criteria others have made available to my evaluative self for judging analytic, evocative and performance autoethnographies. Having acknowledged the dangers and possibilities of such lists attention then turns to how my evaluative self might go about judging a selection of autoethnographies published in Qualitative Research in Sport, Exercise and Health using multiple criteria from a variety of sources. Rather than being purely a cognitive, linear and rational act the process described is messy, tentative, contingent, and deeply embodied as my evaluative self feels its way towards making certain kinds of judgment calls over others.

\section{Introduction}

Over the last two decades, across a variety of disciplines, there has been a growing interest in the genre of qualitative inquiry known as autoethnography as evidenced in books devoted specifically to this topic (e.g., Bochner and Ellis, 2016; Chang, 2008; Jones, Adams and Ellis, 2013; Muncey, 2010; 
Pensoneau-Conway, Adams and Bolen, 2017; Short, Turner and Grant, 2013; Turner, Short, Grant, and Adams, 2018). Likewise an increasing number of autoethnographic articles have appeared in a range of journals. This growing momentum led the University of California Press to launch in 2020 a new online journal called the Journal of Autoethnography.

The journal Qualitative Research in Sport, Exercise and Health (QRSEH) has always been open to receiving autoethnographic work. Indeed, an autoethnography by Brendan Stone called Running Man appeared in the very first edition of the journal in 2009. Since then, at the time of writing, a further 20 autoethnographies have appeared in QRSEH. Of this total of 21, 7 have the word 'autoethnography' in their title while 14 have this word in their abstract or as a keyword.

Of course, if 21 autoethnographies have been accepted for publication in QRSEH, normally after undergoing revisions (major to minor) suggested by reviewers, then I suspect that many more have been rejected along the way. Indeed, as a reviewer, I have rejected some of them in this and other journals that I am associated with as either a member of their advisory of editorial boards. In working towards making my decision to tick the accept, major revisions, minor revisions, or reject box on the QRSEH reviewers form, I put myself forward as an evaluative self that passes judgment on the work of others.

Given the power differentials that exist between me and the anonymous author(s) of the article in front of me, a great deal of responsibility goes with this role, and I take my reviewing duties very seriously indeed. I 
know all too well the searing pain of having an article rejected and the multiple anxieties of making major revisions before the brief serge of exultation when the article finally gets accepted for publication. As part of these responsibilities, in what follows I offer some reflections on how as an evaluative self I go about judging autoethnography in its different guises and the ways in which I call upon various criteria to do so as part of a non-linear, complex, and messy process of embodied engagement.

\section{What's in the name autoethnography?}

For symbolic interactionists, as Charmaz (2006) points out, names classify objects and events and convey meanings and distinctions. For her, names carry weight, whether light or heavy, they provide ways of knowing and being, and are rooted in actions and give rise to specific practices. Thus, when I act as an evaluative self and review a journal article, I am sensitive to the names chosen by the authors to describe their work as this signals their intents and purposes within the framework of a particular tradition of qualitative inquiry. So when I read something like, 'this article provides an autoethnographic account of experience $X$,' I begin to expect something that displays the general characteristics of this genre. This is my first act of judgment as an evaluative self.

Assisting me in this first judgment is the of work various scholars who, without seeking to determine what it is once and for all in an act of closure, have proposed a number of key characteristics that they feel bind the genre of autoethnography together. For example, Holman Jones, Adams and Ellis (2013) list the following characteristics: purposefully commenting on/critiquing 
of culture practices; making contributions to existing research; embracing vulnerability with a purpose; and creating a reciprocal relationship with audiences in order to compel a response. Likewise, Manning and Adams $(2015,205)$ state that two essential qualities should be present in all autoethnographic projects.

First, any work labeled 'autoethnography' should include personal experience and demonstrate, through thoughtful analysis, why this experience is meaningful and culturally significant. An essay that does not use or describe the importance of personal experience in a cultural context should not be considered an autoethnography. Second, this personal experience must be reflexively considered through the use of extant theory, other scholarly writings about the topic, fieldwork observations, analysis of artifacts (e.g., photographs), and/or involvement with others (e.g., interviews). If many of these elements are not evident, then a project should not be considered an autoethnography.

The thoughts above are echoed directly by Adams and Herrmann (2020), the editors of the newly established Journal of Autoethnography, in the guidance they offer to those interested in submitting an article to this journal. While they do not wish to be prescriptive about what autoethnography is or how to do it, Adams and Herrmann state the following.

What makes a particular work an 'auteothnography'?

'Autoethnography' is comprised of three interrelated components: 'auto,' 'ethno,' and 'graphy.' Thus, autoethnographic projects use 
selfhood, subjectivity, and personal experience ('auto') to describe, interpret, and represent ('graphy') beliefs, practices, and identities of a group or culture ('ethno'). Manuscripts published in this journal must engage these components....We expect every manuscript to engage with at least some aspects of the 'auto,' 'ethno,' and 'graphy,' and these components will inform how we assess manuscripts. (pp. 2-3, emphasis added) .

Such guidance and identifying of characteristics are useful in helping my evaluative self to judge if what is being offered to me actually is an autoethnography. Often, in the introduction the author tells me they have produced an autoethnography but none of these key characteristics are present in what follows. Alternatively, the author tells me that their piece contains each of the characteristics named by Adams and Herrmann (2020), Holman Jones et al. (2013) and/or Manning and Adams (2015) above. However, when it comes to showing me these characteristics in action in what follows, none of them are present. My conclusion, therefore, is that wherever the piece is, it is not an autoethnography and I am obliged to point this out to the author in my review. This is a sharp reminder that simply claiming that one has produced an autoethnography does not mean that one has actually done so.

The characteristics provided by Adams and Herrmann (2020), Holman Jones et al. (2013) and Manning and Adams (2015) also help me reflect on the confusions that some authors have regarding autoethnography and other genres such as, for example, an autobiography or a confessional tale. Regarding the former, Holman Jones et al. point out that while all personal 
writing could be considered examinations of culture, not all forms of personal writing are autoethnographic. For them, if an author writes to tell a story to 'illustrate a sad, joyful, or problematic experience but does not interrogate the nuances of this experience in light of general cultural phenomena and cultural practices, the author writes autobiographically' (p. 23). In contrast, they argue, if the author takes the same experience, reflects on its nuances, and then writes intentionally to show how aspects of this experience 'illuminate more general cultural phenomena and/or to show how the experience works to diminish, silence, or deny certain people and stories, then the author writes autoethnographically' (p. 23).

The characteristics named above are reinforced when Adams and Herrmann (2020) state that the use of personal experience does not automatically make a manuscript autoethnographic. For this to happen, 'personal experience must be used intentionally to illuminate and interrogate cultural beliefs, practices, and identities ("ethno")' (p. 2). In some cases this can be a fine distinction for sure. A distinction remains nevertheless and often articles that claim to be autoethnographic are rejected because they are actually autobiographical in nature.

A similar confusion can arise in relation to confessional tales as described by Sparkes (2002a) and Van Maanen (1988) that are distinguished by their highly personalised style and their self-absorbed mandate. Thus, Fortune and Mair (2011) offer a highly reflexive account of their impact as researchers in the production and interpretation of the data generated in their ethnographic study of a small sports club in rural Canada to investigate the role of such clubs as social and community spaces. As part of this self- 
reflexive process, they draw extensively on their field notes to illustrate and problematise how their senses of self and positioning as a graduate assistant (Fortune) and an assistant professor (Mair) interacted to shape their interactions within the curling club, the kinds of data they collected, and the interpretations they consequently made. Specific attention is paid to role relationships, forms of participation, performing, personal issues (relating to background and experiences), and maintaining balance and distance. Their self-revealing text illustrates the problems that ethnographers have to grapple with on a regular basis, such as, power, ethics, representation, voice, subjectivity and interpretation.

Having done all the above, and despite being very self-reflexive and self-revealing, Fortune and Mair (2011) do not claim their article is an autoethnography. Rather, they accurately, in my view, name it as a confessional. Others are less precise in their naming and often confuse methodological reflections based on their personal experiences (extremely important as these are), with autoethnography. Interestingly, in her reflections on the current state of autoethnography through her experiences as a reviewer of autoethnographic manuscripts, Stahlke Wall (2016) expresses a similar concern. Looking back at her reviews she notes a tendency for authors to apply the label autoethnography to purposes that might have been labeled otherwise before the idea of autoethnography rose to popularity. Stahlke Wall notes that one author referred to her work as autoethnographic because she was writing about her self-reflections in the process of qualitative data analysis in a specific research project.

As I said to her, I 'wonder if there is a line between what can be 
considered autoethnographic and what is perhaps more appropriately thought of as accounting for self or locating oneself in the research.' Similarly, another manuscript was essentially 'a reflection on the research process.' Again, I expressed to the author my concerns about using autoethnography as a method in his or her particular case. (Stahlke Wall, 2016, 3)

As part of her reflections, Stahlke Wall (2016) acknowledges that while there are certainly blurred boundaries in research, most autoethnographies deal with substantive topics/phenomena of sociological interest. Therefore, based on her review of these manuscripts, she concluded that the 'reflexive analysis of research experiences should not be labeled as autoethnographic. Even though they serve an important purpose, they are essentially methodological articles rather than explorations of substantive social issues' (p. 4). Regardless of whether one agrees with Stahlke Wall's view, or my comments earlier about the confusions between confessional tales and autoethnography, they give food for thought to authors about the names they attach to their work and whether of not the choice of autoethnography is appropriate for what they have actually submitted for review.

\section{On judging different kinds of autoethnography}

Once my evaluative self has made a judgment on whether or not the article submitted actually is an autoethnography, my attention turns its 'quality'. Often, people feel that writing and autoethnography is an easy option. It most certainly is not. As Spry (2001) reminds us, the writing of an autoethnography must be well crafted and capable of being respected from both a literary and a 
social scientific point of view. For her, 'mediocre writing in any venue lacks the ability to transform readers and transport them into a place where they are motivated to look back on their own personally political identity construction' (p. 713). Mediocre writing, therefore, is likely to lead to the presentation of a mediocre autoethnography that then leads to a rejection. In part, this has led me to begin such rejections or calls for major revisions with the following lines.

I appreciate and thank the author for seeking to share with me his/her experiences of (named phenomenon) and its impact on her/his life. Unfortunately, having such experiences and attempting to share them in written form is no guarantee that a 'good' and satisfying autoethnography is produced for the reader.

Following on from this, I often feel obliged to raised issues about the nature of the stories told and how they are presented to me as a reader.

For me the stories provided about the author's experiences of (phenomenon) are problematic. They tend to read as rather flat accounts rather than rich descriptions with vivid scenes to contextualise the interactions of those involved in ways that take the reader into the action. The landscape presented, therefore, is somewhat bare. The characters (including that of the author) are presented as disembodied beings as opposed to fleshy, rounded, complex and nuanced beings. The people mentioned have no personalities and no histories and come across as free-floating quotes that the author then uses in his/her 'interpretation section.'

Of course, my comments above immediately begs the question as to what I feel constitutes a 'good and satisfying' autoethnography beyond 'just' the 
quality of the writing? I wish I could give a simple answer but I can't because to do so would insinuate, as a criteriologist might, that I have access to, or believe in the possibility of a set or list of foundational, universal, rigid, and unmovable criteria that can be applied to anything that claims the name of ‘autoethnography' regardless of its intentions and purpose (Sparkes \& Smith, $2009,2014)$. This is not the case because just how the characteristics of autoethnography outlined by Adams and Herrmann (2020), Holman Jones et al. (2013), and Manning and Adams (2015) are played out in practice is very much up for grabs and open to a range of interpretations that need to be judged accordingly.

There is no one definitive form or containing category of autoethnography owned by individual scholars regarding how it should be done, or how it should be represented. Rather, as McMahon (2016) points out, there are many variations and possibilities that lead to different kinds of autoethnography. Here are but a few on offer: analytic autoethnography (Anderson, 2006), Black feminist autoethnography (Griffin, 2012), collaborative autoethnography (Chang, 2012), community autoethnography (Toyosaki et al., 2009), critical autoethnography (Boylorn \& Orbe, 2016), evocative autoethnography (Bochner \& Ellis, 2016), impressionistic autoethnography (Skinner, 2003), indigenous autoethnography (Whitinui, 2014), interpretive autoethnography (Denzin, 2014), meta-autoethnography (Ellis, 2009), performance autoethnography (Denzin, 2018), performative autoethnography (Spry, 2011), phenomenological autoethnography (Regina, Aguirre \& Duncan, 2013), poetic autoethnography (Speedy, 2015), and psychoanalytic autoethnography (Garratt, 2014). 
Given the variation described above, different criteria need to be drawn upon for judging these different kinds of autoethnography. Starting from scratch this could be an overwhelming task. Assistance has however been provided by a number of scholars who have constructed lists of criteria they feel are relevant to judging the kind of autoethnography they advocate (Sparkes, 2018a, 2018b). To illustrate this point, and for the purposes of discussion, I will now consider some lists offered for judging analytic, evocative and performance autoethnography.

\section{Analytic autoethnography}

According to Anderson (2006), analytic autoethnography has the following five key features: complete member researcher status, analytic reflexivity, narrative visibility of the researcher's self, dialogue with informants beyond the self, and a commitment to theoretical analysis. For him, the purpose of analytic autoethnography is not just about documenting personal experience, providing an insider's perspective or evoking emotional resonance with the reader. Rather it is about, using empirical data 'to gain insight into some broader set of social phenomena than those provided by the data themselves' (p. 387). In this respect, according to McMahon (2016, 307), analytic autoethnography represents a more 'traditional scientific' autoethnographic approach, 'with a focus both on telling readers what the tale is about and how it should, ideally, be read.'

Drawing on Anderson's (2006) work, others have developed his approach and the criteria used to judge both its processes and products. For example, speaking of how health researchers can produce desirable (i.e., analytic) 
autoethnographies that potentially contribute to advancing health-related knowledge, Chang $(2016,448)$ offers the following five standards (i.e., criteria) for judging the quality of such work.

- Authentic and Trustworthy Data: Does the autoethnography use authentic and trustworthy data?

- Accountable Research Process: Does the autoethnography follow a reliable research process and show the process clearly?

- Ethics Toward Others and Self: Does the autoethnography follow ethical steps to protect the rights of self and others presented and implicated in the autoethnography?

- Sociocultural Analysis and Interpretation: Does the autoethnography analyze and interpret the sociocultural meaning of the author's personal experiences?

- Scholarly Contribution: Does the autoethnography attempt to make a scholarly contribution with its conclusion and engagement of the existing literature?

Like Anderson (2006), Chang $(2016,445)$ also signals that her criteria, along with her suggestions for what she describes as probably the most systematic process of autoethnographic research proposed regarding data collection, organization, analysis, and interpretation, 'may stand contrasted with more fluid approaches of evocative and narrative autoethnography and of interpretive and performative autoethnography'.

\section{Evocative autoethnography}

According to McMahon (2016), evocative autoethnography can also be 
referred to emotional autoethnography. For her, this kind of autoethnography involves a literary approach to research that seeks to show rather than tell the reader about the subjective emotional experiences of the author. This showing accomplished by creating compelling stories that invite the reader to feel an emotional resonance and connection with the author, as well as gain an understanding of the culture central to the story being told.

With regard to evaluating evocative autoethnography Bochner and Ellis (2016) offer some reflections in the form of a conversation between them and a group of students. They point out that depending upon the kind of autoethnography you are doing, the criteria by which it should be evaluated will be different. For Bochner and Ellis, if you are aspiring do something akin to analytic autoethnography, then the criteria 'should be more social scientific, such as considerations of validity, data collection, categorization processes, and generalizability across cases' (p. 212). If, however, you aspire to an evocative form of autoethnography then, they suggest, you will not be so concerned with these issues. To illustrate this point, as part of their conversation with their students, Bochner offers the following list of criteria he uses for evaluating evocative autoethnography.

- I look for abundant, concrete details. I want to feel the flesh and blood emotions of people coping with life's contingencies.

- I am attracted to structurally complex narratives that are told in a temporal framework representing the curve of time.

- I also reflect on the author's emotional credibility, vulnerability, and honesty. I expect evocative autoethnographers to examine 
their actions and dig underneath them, displaying the self on the page, taking a measure of life's limitations, of cultural scripts that resist transformation, of contradictory feelings, ambivalence, and layers of subjectivity, squeezing comedy out of life's tragedies.

- I also prefer narratives that express a tale of two selves, one that shows a believable journey from who I was to who I am, and how a life course can be reimagined or transformed by crisis.

- I hold the author to a demanding standard of ethical selfconsciousness ... I want the writer to show concern for how other people in the teller's story are portrayed, for the kind of person one becomes in telling one's story, and to provide space for the listener's becoming.

- I want a story that moves me, my heart and belly as well as my head; I want a story that doesn't just refer to subjective life, but instead acts it out in ways that show me what life feels like now and what it can mean. (Bochner \& Ellis, 2016: 212- 213).

\section{Performance autoethnography}

In performance autoethnography, according to McMahon $(2016,309)$, the autoethnographer/story teller/researcher can be likened to the lead actor in their own story through a theatrical performance that 'brings to life or to the stage/theatre transcribed or text-based lived experience'. Here, she suggests, the lead actor 'enacts the performance in storied form, particularly in terms of the specific cultural context within the performance' (p. 309). 
Reflecting upon the possibilities of criteria for evaluating performance autoethnography, Holman Jones $(2005,773)$ developed a list of actions and accomplishments she looks for in the work of others. These are as follows:

- Participation as reciprocity: How well does the work construct participation of authors/readers and performer/audiences as a reciprocal relationship marked by mutual responsibility and obligation?

- Partiality, reflexivity, and citationality as strategies for dialogue (and not mastery): How well does the work present a partial and selfreferential tale that connects with other stories, ideas, discourses, and contexts (e.g., personal, theoretical, ideological, cultural) as a means of creating a dialogue among authors, readers, and subjects written/read?

- Dialogue as a space of debate and negotiation: How well does the work create a space for and engage in meaningful dialogue among different bodies, hearts, and minds?

- Personal narrative and storytelling as an obligation to critique: How do narrative and story enact an ethical obligation to critique subject positions, acts, and received notions of expertise and justice within and outside of the work?

- Evocation and emotion as incitements to action. How well does the work create a plausible and visceral lifeworld and charged emotional atmosphere as an incitement to act within and outside the context of the work?

- Engaged embodiment as a condition for change. How does the work place/embody/interrogate/intervene in experience in ways that make 
political action and change possible in and outside the work?

Similarly, Denzin $(2018,197)$ offers the following criteria to help us evaluate whether or not performance texts are successful, or not, in accomplishing the following:

- Unsettle, criticize and challenge taken-for-granted, repressed meanings

- Invite moral and ethical dialogue while reflexively clarifying their own moral position

- Engender resistance and offer utopian thoughts about how things can be made different

- Demonstrate that they care, that they are kind

- Show, instead of tell, while using the rule that less is more

- Exhibit interpretive sufficiency, representational adequacy, and authentic adequacy

- Are political, functional, collective, and committed.

\section{Working with lists: Dangers and possibilities for the evaluative self}

The lists provided above by others for how my evaluative self might pass judgment on different kinds of autoethnography (or any form of qualitative inquiry) are both helpful and dangerous (Sparkes, 2018a, 2018b). They are dangerous in that they can provide a false sense of security. Here, all I have to do if the author claims their work to be analytic, evocative or performance based, or uses words that suggest it is one of these types, is to take the list of criteria attached to each one by the scholars above (assuming that I understand what they actually mean by their criteria) and apply them directly 
to the piece in front of me. Such a mechanistic, prescriptive, and normative application of a list, however, can serve a strong exclusionary and legitimation function by regulating the boundaries of specific forms of autoethnography and thereby control its practitioners in punitive ways.

Lists can quickly become a rigid and inflexible quality appraisal 'checklist' that is then used by the evaluative self to set standards of 'quality control.' Thus, the lists proposed above by Anderson, Chang, Bochner and Ellis, Holman Jones, and Denzin become the lists for judging their preferred genres of autoethnography at the exclusion of all others. The list then operates as a fixed recipe that all must follow which then leads to rigid standardization at the cost of innovation. In such circumstances, as GingrichPhilbrook (2013) points out, the checklist gets confused for a meta-language and something that is universally endorsed. Such lists, he argues, can too quickly get converted into a magic contract for power relations whereby the evaluative self proceeds to make publication assessments guided by that view that any absence of criteria from the list should be defined as a 'deficit' in the work. Smith and Deemer $(2000,888)$ clearly warn against such an approach:

The use of the term list should not be taken to mean that we are referring to something like an enclosed and precisely specified or specifiable shopping or laundry list. Put differently, to talk of a list in this sense is not at all to talk about, for example, an accumulation of 20 items, scaled 1 to 5 , where everyone's presentation proposal is then numerically scored with a cutoff point for acceptance. Obviously, to think of a list in these terms is to miss the entire point. 
For my evaluative self to avoid missing the entire point, Smith and Deemer (2000) suggest that any list of criteria, or characteristics as they call them, should be seen as always open-ended, and ever subject to constant reinterpretation so that items can be added to the list or taken away. Therefore, the criteria used to judge a piece of research can change depending upon the context and the purposes. This is because a characteristic of research we thought important at one time and in one place may take on diminished importance at another time and place.

From the more flexible position and relativistic position advocated above, Barone and Eisner (2012) argue that any list of criteria on offer, including their own for arts-based inquiry, are to be used as cues for perception and starting points for thinking that may be useful and relevant to the work they are encountering at the time. My evaluative self in taking any list of criteria as a cue for perception and a starting point is crucial in addressing another danger of lists. The danger here is that lists imply that different types of autoethnography are pure and discreet entities with hermetically sealed and impermeable boundaries. That is, each type is mutually exclusive, and one either does analytic autoethnography, or one does evocative autoethnography, or one does performance autoethnography in accordance with specific lists of criteria for each genre. No mixing is possible. Such a view is highly problematic and, in my experience, does not hold up to scrutiny ${ }^{1}$.

Analytic autoethnography, for example, can include evocation and emotionally rich texts and this is not incompatible with analysis. Both Hayler (2013) and Winkler (2018), therefore, reject the notion that evocative and 
analytic autoethnography need be mutually exclusive, and note that a fruitful combination can enlarge the spectrum of autoethnographic research and open up further possibilities for development. All of which leads Tedlock (2013) to call for the braiding of evocative with analytic autoethnography in ways that produce powerful writing about the self in the world in order to help change the world.

Against the backdrop described above, Tullis $(2013,245)$ believes that autoethnography 'exists on a continuum from highly fluid and artistic to formulaic and highly analytic.' Likewise, Stahlke Wall $(2016,3)$ argues that the 'dichotomy of evocative versus analytic autoethnography is more a continuum than a binary, and there are examples of autoethnographic work that fall at all points along it.' In terms of a continuum, Manning and Adams (2015) identify the four common orientations that many autoethnographers use to design, conduct, represent, and evaluate autoethnographic projects. These are as follows: social scientific autoethnography (i.e., analytic autoethnography in Anderson's, 2006, terms); interpretive-humanistic autoethnography; critical autoethnography; and creative-artistic autoethnographies.

Importantly, Manning and Adams $(2015,191)$ point out that although they list four distinct orientations, 'it is not unusual for autoethnographers to blend the goals and techniques of each in a single project or as they write about the same experiences over time'. Likewise, Adams and Herrmann $(2020,3)$ note the following.

Some manuscripts will foreground personal experience ('auto') and evocative representation ('graphy') but may implicitly reference extant 
research or discern patterns of social interaction ('ethno'). Some manuscripts will use personal experience ('auto') alongside formal interviews or artifacts ('ethno') but may be more structured with representing the research ('graphy').

All the views expressed above suggest that the boundaries of autoethnographic types or orientations in terms of the balance between showing and telling, and the lists of criteria associated with them, should not be viewed as rigidly bounded systems but as something more permeable and fluid in nature, which allows them to be used in a creative rather than a conservative and formulaic manner.

\section{Reflections of my evaluative self on a selection of autoethnographies published in QRSEH ${ }^{2}$}

The need for my evaluative self to be flexible and creative in selecting criteria for judging different forms of autoethnography rather than a slave to any given list is made evident in my following reflections on a number of autoethographies published in QRSEH that have braided the analytic with the evocative. For example, in what constitutes a collaborative autoethnography, Ing and Mills (2019) provide some evocative and well-crafted stories about Ing's experiences in sport as a youngster living with Attention Deficit Hyperactivity Disorder (ADHD), and his feelings when, as a new coach at a football academy working with a team of 10 year olds he has to deal with an incident between two players, one of whom he later learns has ADHD.

To begin with Ing and Mills open with an explanation of ADHD. Then, following Sparkes (2004) they employ a personal and academic voice 
framework in order to highlight the differences between relived experiences (i.e. personal voice) and sections that provide explanation and signpost the readers to useful scholarly content (i.e. academic voice). Thus, a story of 'losing it' is told in a personal voice before the authors step back to reflect on the meanings of this story using their 'academic voice' that draws upon the literature and is analytic in nature. The same braiding process takes place with the next story, 'It's not just me' which is told in a personal voice followed by the analytic reflections of the academic voice. The discussion that closes the article considers the implications of what the stories reveal about living with ADHD in relation to practices and policies in sport. This combination of showing and telling by Ing and Mills succeeds in combining the power of the personal perspective with the value of analysis and theory as advocated by Stahlke Wall (2016).

A similar strategy of combining his personal voice in the form of rich, contextualized vignettes and his academic (analytic) voice is used by Mills (2015) as he explores his experiences of constructing, deconstructing and partially reconstructing his coaching identity over time. Likewise, Cronin, Ryrie, Huntley and Hayton (2018) juxtapose relativist vignettes (personal voice) with academic voices that analyse each vignette as part of their coconstructed autoethnography that, by drawing on observational data, reflective field notes, and interviews proceeds to examine Cronin's experiences as a basketball coach who enters a youth club for disabled participants for the first time.

Other authors in QRSEH have also fruitfully combined personal stories 
with analytic reflections framed by various theories and concepts to assist the reader in making their interpretations. For example, Scarfe and Marlow (2015) offer a phenomenologically informed autoethnography of the first author's identity conflict as a runner when she is diagnosed with epilepsy, and her ensuing identity dilemmas when she returns to running after this diagnosis. In contrast, Zehntner and McMahon (2014) draw on Foucauldian theory to explore the first author's experiences as a swimming coach and her mentormentee relationships as shaped within the culture of Australian swimming. Likewise, Peers (2012) draws on Foucauldian theory but also connects to critical disability theory to interrogate the role of parasport in the formation, disciplining and internalizing of his own (in)coherent disabled Paralympian identity. The work of Foucault also informs the work of Gibson (2012) but is integrated with the literature on consumerism, the culture industry, technoscience and cyborg theory to explore how these interact to shape the experiences of runners, and their practices when they buy running shoes.

The work cited above, make clear the inappropriateness of my evaluative self applying just the list of criteria for analytic autoethnography proposed by Chang (2016), or just the list of criteria for evocative autoethnography proposed by Bochner and Ellis (2016) when passing judgment. Each list is simply not sufficient on its own for doing a fair and proper job. Given that the authors above have skillfully combined the analytic and evocative in their autoethnographies then, at the very least, my evaluative self must select relevant criteria from both these lists (and others) in judging such work. Thus, for example, following Chang I can ask whether or not an article makes a scholarly contribution in terms of its conclusion and 
engagement with the existing literature, and I can also ask following Bochner and Ellis if the personal stories presented express a tale of two selves, one that shows a believable journey from who the author was to who they are now, and how a life course can be reimagined or transformed by the experiences they have encountered along the way.

As an evaluative self my selection and mixing from various lists of criteria will necessarily be influenced by the balance of telling and showing in the autoethnography on offer and where I feel the author positions themselves on this continuum. This is particularly so in relation to work that aspires to evoke a response from the reader. Thus, in seeking to produce an evocative autoethnographic text that interrogates and explores novel engagements (both his own and those of readers) with mind/body (dis)connections in ways that invite readers to engage with rather the than simply read (i.e. be told) about his (dis)embodied experiences, Laurendeau (2019) opts to emphasize showing over telling. For sure, some academic references are cited on one page of the article but the majority are located in the notes section at the end. This clearing of academic references and the telling that accompanies this, opens up the space for Laurendeau to craft a layered, embodied, introspective and relational story that tries to understand and express what he is thinking, feeling and experiencing physically as he attempts to adapt gracefully in his ageing body.

In relation to Laurendeau's work, I am immediately drawn to the criteria contained in the list offered by Bochner and Ellis' (2016) for evocative autoethnography in terms of looking for abundant, concrete details, wanting to 
feel the flesh and blood emotions of people coping with life's contingencies, and being attracted to structurally complex narratives that are told in a temporal framework representing the curve of time. Given the performance dynamics of Laurendeau's stories, however, I am also drawn to criteria in the lists provided by Denzin (2018) and Holman Jones (2005) in terms of how the text unsettles, criticizes and challenges taken-for-granted, repressed meanings and creates a space for engaging in meaningful dialogue among different bodies, hearts, and minds. But then I think about other relevant criteria from different lists that are available such as the one offered by Barone (2011) as he reflects on the twelve contrasts that he feels exist between a flat piece and an engaging piece. I am drawn to many of his contrasts such as the following one.

The flat piece, a cold dinner, is forced down, taken in with little pleasure. It lacks the heat of the chef's passions, the chef's sensuous self who knows, without spice, all is bland. The engaging piece makes each mouthful worthy of comment, encourages lingering, savoring, remembering. In it's presence, I want to invite my colleagues and students to enjoy its flavors. (p. 666)

The process described above regarding the ways in which my evaluative self gets drawn towards some criteria over others from different sources when passing judgment on evocative authoethnographies is far from being a purely cognitive, rational, and linear process. Rather it is deeply embodied. For sure, my head is involved but so is my heart and my viscera as I not only think 
about the stories I read but also with them in terms of their relationship with me as a similarly aged, vulnerable, corporeal and enfleshed being.

My evaluative self goes though a similar, but never an identical process, when I engage with other autoethnographies that rely more on showing rather than telling, such as, the embodied, introspective and relational story provided by Ellis (2015) of her gradual adaption over time to the chronic pain and deterioration caused by osteoarthritis in her hip. Likewise, Stone (2009) only cites one academic reference in his evocative autoethnography which explores his experiences of anorexia, excessive exercising and psychosis, and which links the starvation of the body to the repression of traumatic memory. Again, as with the work of Laurendeau (2019), I am drawn to some of the criteria provided by Bochner and Ellis (2016), Holman Jones (2005), and Denzin (2018).

I am also drawn to some of the criteria in the list offered by Barone and Eisner (2012) for judging arts based research. For example, they speak of concision. This criterion pertains to the degree to which the arts based research 'occupies the minimal amount of space or includes the least amount of verbiage necessary for it to serve its primary, heuristic purpose of enabling members of the audience to see social phenomena from a fresh perspective' (p. 148). In thinking about the concision of the article in front of me, I then connect to the following characteristic provided by Barone $(2011,666)$ whereby the engaging piece 'knows just how to dress for the occasion, perhaps adorning itself in the unfamiliar but always with an eye toward making any flourish and expressive part of the whole. Instead of ostentatious display, its design encourages further conversation.' This rhizomic process continues 
as I engage with the story being told and make connections with criteria that I feel, but never know for sure, are relevant and appropriate to what I think the author is trying to achieve in their work.

The rhizomic process involved in making judgments is invoked once again when I engage with performance autoethnography as described earlier, and offered by Douglas (2014) in her four act play called Revised Reshaped Reclaimed. Here, drawing upon her previous experiences as professional golfer, the performance autoethnography crafted by Douglas is intended to explore the tensions, contradictions and consequences of stories in elite sport and raise questions about how the socially constructed physical 'l' is created by those with interpretive privilege, such as, those in the sports news media. She does this by using sports media stories collected over a 14-year period about her that focused on 'sporting excellence', and contrasts these with diary extracts, stories, poems and songs, written by her to generate an alternative reflexive understanding of her self, identity and life playing professional sport. This data forms the basis of Revised Reshaped Reclaimed.

In terms of passing judgment on the performance autoethnography I am assisted by the analytic reflections provided by Douglas at the end of her article that assist the reader by offering guidance on how events portrayed in Revised Reshaped Reclaimed might be interpreted. Here, she draws on narrative theory to make the case that her work offers a counterstory that challenges and resists the oppressive dynamics of the dominant cultural narrative in sport that revolves around performance. For her, this counterstory sets out to repair damage inflicted by an oppressive dominant narrative, free her moral agency, provide a template for other athletes to consider their 
identities and relationships, and also be an act of purposive moral selfdefinition. Given this political intent, I am drawn to the thoughts of Holman Jones (2005) regarding engaged embodiment as a condition for change, and how the counterstory offered by Douglas works to place/embody/interrogate/intervene in experience in ways that make political action and change possible in and outside the work. Linked to this are Denzin's (2018) criteria of whether or not the performance autoethnography unsettles, criticizes, and challenges taken-for-granted, repressed meanings, engenders resistance and offers utopian thoughts about how things can be made different.

As before, my use of criteria is not confined to those included in lists developed by Denzin (2018) and Holman Jones (2005) specifically for judging performance autoethnography. Again, I am drawn to the list of criteria provided by Barone and Eisner (2012) for arts based research in terms of concision as explained above in relation to me judging evocative autoethnographies. As I reflect on the article by Douglas (2014), I also think about how Barone and Eisner say that a good piece of arts based research should illuminate a terrain, a process, an individual in ways that sheds light by defamiliarizing an object or process so that it can be seen in a way that is entirely different from how it might be seen when customary modes of perception operate. From this, I move to Barone's $(2011,666)$ observation that an engaging piece 'exists in struggle, searching for what it may come to realize. It becomes a small, nervous solution, offered with humility. Its ideas slide into cautions claims, noting its limitations.' 
But, of course, given the permeable boundaries that exist between different types of autoethnography, these same thoughts can also occupy me when I read an evocative autoethnography. It also needs to be noted that my comments about the kind of criteria I might call upon to judge the performance autoethnography offered by Douglas (2014) are based on me reading this as a written text, and not seeing/hearing it as a live performance on the stage with an audience reacting to it. Here, as Cho and Trent $(2009,11)$ point out, the performance in use involves 'transacting the lived experiences of others to audiences by means of voices and bodies of the performer(s).' Given this change in transactional context in which, as Pelias (1992) reminds us, the performer carries the obligation to fashion an aesthetic form while I as an audience member have the burden of response, then, once again, my modes of judgment will necessarily shift accordingly.

\section{Closing comment}

If nothing else, I hope that the reflections of my evaluative self reveal the complexities, for me at least, of passing judgment on different forms of autoethnography. It's a messy, tentative, contingent process in which I feel my way into the piece in front of me, reading it multiple times with gaps in between where a cocktail of thoughts and emotions mingle in my body as I drift towards certain kinds of judgment call over others ${ }^{3}$.

As evidenced above, my evaluative self draws on lists of criteria provided by others with specific interests, both personal and political, for promoting their lists over others. These lists are certainly useful as starting points but they are not enough on their own. As Le Roux (2017) emphasizes 
any set of lists cannot substitute for informed judgment and that any appraisal of autoethnographies should be subject to individual judgment based on insight and experience. This appeal to insight, imagination, and informed, principled judgment is echoed in the notion of the connoisseur advocated by Sparkes and Smith $(2009,2014)$ that involves the art of appreciation and the ability to make fine-grained discriminations among complex and subtle qualities (Eisner, 1991). Whether or not my evaluative self actually does achieve the status of the connoisseur when it comes to judging autoethnography, or any other kind of qualitative research, is open to question. But, at least I aspire to do so and, I guess, that's the best I can do.

\section{Notes}

1 This experience includes my own forays into the domain of autoethnography where I have tried to braid evocative storytelling with various forms of conceptual analysis (e.g., see Sparkes, 1996, 2002b, 2003, 2007, 2012, 2013, 2016; Sparkes \& Smith, 2012).

2 The reader should not assume that the author reviewed any of the articles cited in this section.

${ }^{3}$ Some of the criteria I have drawn on to pass judgment on autoethnography could also be used to judge ethnographic nonfictions and other creative analytic practices. Regardless of the genre and the criteria drawn upon, for me, the judgment process remains messy, tentative, contingent and deeply embodied.

\section{References}

Adams, T., Holman Jones, S. and Ellis, C., 2015. Autoethnography: 
Understanding qualitative research. Oxford: Oxford University Press.

Adams, T. and Herrmann, A., 2020. Expanding our autoethnographic future. Journal of Autoethnography, 1, 1-8.

Anderson, L., (2006). Analytic autoethnography. Journal of Contemporary

Ethnography, 35, 373-395.

Barone, T. and Eisner E., 2012. Arts based research. London: Sage.

Bochner, A. and Ellis, C., 2016. Evocative autoethnography: Writing lives and telling stories. London: Routledge.

Boylorn, R., and Orbe, M., 2016, eds. Critical autoethnography: Intersecting cultural identities in everyday life. Walnut Creek, CA: Left Coast Press.

Chang, H., 2008. Autoethnography as method. Walnut Creek, CA: Left Coast Press.

Chang, H., 2012. Collaborative autoethnography. London: Routledge.

Chang, H., 2016. Autoethnography in health research: Growing pains?

Qualitative Health Research, 26, 443-451.

Charmaz, C., 2006. The power of names. Journal of Contemporary

Ethnography, 35, 396-399.

Cho, J. and Trent, A., 2009. Validity criteria for performance-related qualitative work qualitative research. Qualitative Inquiry, 15, 1013-1041. 
Cronin, C., Ryrie, A., Huntley, T. and Hayton, J., 2018. 'Sinking and swimming in disability coaching': An autoethnographic account of coaching in a new context. Qualitative Research in Sport, Exercise and Health, 10, 362-377.

Denzin, N., 2014. Interpretive autoethnography (2nd ed.). Thousand Oaks: Sage.

Denzin, N., 2018. Performative autoethnography. London: Sage.

Douglas, K., 2014. Challenging interpretive privilege in elite and professional sport: One [athlete's] story, revised, reshaped and reclaimed. Qualitative Research in Sport, Exercise and Health, 6, 220-243.

Eisner, E., 1991. The enlightened eye. New York: Macmillan.

Ellis, C., 2009. Revision: Autoethnographic reflections on life and work. Walnut Creek, CA: AltaMira Press.

Elllis, C., 2014. No longer hip: Losing my balance and adapting to what ails me. Qualitative Research in Sport, Exercise and Health, 6 (1), 1-19.

Fortune, D. and Mair, H., 2011. Notes from the Sports Club: Confessional Tales of Two Researchers. Journal of Contemporary Ethnography, 40, $457-484$

Garratt, D., 2014. Psychoanalytic-autoethnography: Troubling natural bodybuilding. Qualitative Inquiry, 21, 343-353. 
Gibson, K., 2012. Knight's children: Techno- science, consumerism and running shoes. Qualitative Research in Sport, Exercise and Health, 4, 341-361.

Gingrich-Philbrook, C., 2013. Evaluating (evaluations of) autoethnography. In: S. Holman Jones, T. Adams and C. Ellis, eds. Handbook of autoethnography. Walnut Creek, CA: Left Coast Press, 609-626.

Griffin, R., 2012. I AM an angry Black woman: Black feminist autoethnography, voice, and resistance. Women's Studies in Communication, 35, 138-157.

Hayler, M., 2013. When we got to the top of Elm Road. In: N. Short, L. Turner and A. Grant, A., eds. Contemporary British autoethnography. Rotterdam: Sense Publishers, 17-32.

Holman Jones, S., 2005. Autoethnography: Making the personal political. In: N. Denzin and Y. Lincoln, eds. The Sage Handbook of qualitative research. London: Sage, 763-791.

Holman Jones, S., Adams, T., and Ellis, C., 2013. Introduction: Coming to know autoethnography as more than a method. In: S. Holman Jones, T. Adams and C. Ellis, eds. Handbook of autoethnography. Walnut Creek, CA: Left Coast Press, 17-47.

Ing, C. and Mills, J., 2019. 'Hey, look at me': An \{auto\}ethnographic account of 
experiencing ADHD symptoms within sport. Qualitative Research in Sport, Exercise and Health, 11, 274-283.

Laurendeau, J., 2019. 'You don't need any of that stuff': (Re)stor(y)ing my(nd/) body, Qualitative Research in Sport, Exercise and Health, 11, 246-257.

Muncey, T., 2010. Creating autoethnographies. London: Sage.

Peers, D., 2012. Interrogating disability: The (de)composition of a recovering Paralympian, Qualitative Research in Sport, Exercise and Health, 4, 175-188.

Le Roux, C., 2017. Exploring rigour in autoethnographic research. International Journal of Social Research Methodology, 20, 195-207.

McMahon, J., 2016. Creative analytical practices. In: B. Smith \& A. Sparkes, eds, Routledge handbook of qualitative research in sport and exercise. London: Routledge, 302-315.

Mills, J., 2015. An [AUTO]ethnographic account of constructing, deconstructing, and partially reconstructing a coaching identity. Qualitative Research in Sport, Exercise and Health, 7, 606-619.

Pelias, R., 1992. Performance studies: The interpretation of aesthetic texts. 
Dubuque, IA: Kendall/Hunt

Pelias, R., 2011. Writing into position: Strategies for composition and evaluation. In: N. Denzin and Y. Lincoln, eds. The Sage handbook of qualitative research. London: Sage, 659-668

Pensoneau-Conway, S., Adams, T. and Bolen, D., 2017, eds. Doing autoethnography. Rotterdam: Sense Publishers

Regina T., Aguirre, P \& Duncan, C., 2013. Being an Elbow: A phenomenological autoethnography of faculty-student collaboration for accommodations, Journal of Teaching in Social Work, 33, 531-551.

Scarfe, S. and Marlow, C., 2015. Overcoming the fear: an autoethnographic narrative of running with epilepsy, Qualitative Research in Sport, Exercise and Health, 7, 688-697.

Smith, J., and Deemer, D., 2000. The problem of criteria in the age of relativism. In: N. Denzin and Y. Lincoln, eds. Handbook of qualitative research. London: Sage, 877-896.

Short, N., Turner, L and Grant, A., 2013, eds. Contemporary British autoethnography. Rotterdam: Sense Publishers.

Skinner, J., 2003. Montserrat Place and Mons'rat Neaga:isepien Example of Impressionistic Autoethnography. The Qualitative Report, 8, 513-529. 
Sparkes, A., 1996. The fatal flaw: A narrative of the fragile body-self. Qualitative Inquiry, 2, 463-495.

Sparkes, A., 2002a. Telling tales in sport and physical activity: A qualitative journey. Champaign, IL: Human Kinetics Press.

Sparkes, A., 2002b. Autoethnography: Self-indulgence or something more? In: A. Bochner and C. Ellis, eds. Ethnographically speaking: Autoethnography, literature, and aesthetics. London: Altamira Press, 209-232.

Sparkes, A., 2003. Bodies, identities, selves: Autoethnographic fragments and reflections. In: J. Denison and P. Markula, eds. "Moving writing": Crafting movement and sport Research. New York: Peter Lang, 51-76.

Sparkes, A., 2004. From performance to impairment: A patchwork of embodied memories. In: J. Evans, B. Davies and J. Wright, eds. Body knowledge and control: Studies in the sociology of physical education and health. London: Routledge, 157-172.

Sparkes, A., 2007. Embodiment, academics, and the audit culture: A story seeking consideration. Qualitative Research, 7, 519-548.

Sparkes, A., 2013. Autoethnography at the will of the body: Reflections on a failure to produce on time. In: N. Short. L. Turner and A. Grant, eds. British contemporary autoethnography. Netherlands: Sense Publishers, 203-212. 
Sparkes, A., 2012. Fathers and sons: In bits and pieces. Qualitative Inquiry, $18,167-178$.

Sparkes, A., 2016. Ageing and embodied masculinities in physical activity settings: From flesh to theory and back again. In: E. Tulle and C. Phoenix, eds. Physical activity and sport in later life: Critical approaches. London: Palgrave, 137-148.

Sparkes, A., 2018a. Creating criteria for evaluating autoethnography and the pedagogical potential of lists. In: L. Turner, N. Short, A. Grant and T. Adams, eds. International perspectives on autoethnographic research and practice. London: Routledge, 256-267.

Sparkes, A., 2018b. Autoethnography comes of age: Consequences, comforts, and concerns. In: D. Beach, C. Bagley and S. Marques da Silva, eds. The Wiley handbook of ethnography of education. London: Wiley, 479-499.

Sparkes, A. and Smith, B., 2009. Judging the quality of qualitative inquiry: Criteriology and relativism in action. Psychology of Sport and Exercise, $10,491-497$.

Sparkes, A. and Smith, B., 2012. Narrative analysis as an embodied engagement with the lives of others. In: J. Gubrium and J. Holstein, eds. Varieties of narrative analysis. London: Sage, 53-73.

Sparkes , A. and Smith, B., 2014. Qualitative research methods in sport, exercise and health: From process to product. London: Routledge. 
Speedy, J., 2015. Staring at the park: A Poetic autoethnographic inquiry.

Walnut Creek, CA: Left Coast Press,

Spry, T., 2001. Performing autoethnography: An embodied methodological praxis. Qualitative Inquir,y 7, 706-732.

Spry, T., 2011. Body, paper, stage: Writing and performing autoethnography. London: Routledge.

Stahlke Wall, S., 2016. Toward a moderate autoethnography. International Journal of Qualitative Methods, January-December, 1-9.

Stone, B., 2009. Running man. Qualitative Research in Sport and Exercise, 1, 67-71.

Tedlock, B., 2013. Introduction: Braiding evocative and analytic autoethnography. In: S. Holman Jones, T. Adams and C. Ellis, eds. Handbook of autoethnography. Walnut Creek, CA: Left Coast Press, 358-362.

Toyosaki, S., Pensoneau-Conway, S., Wendt, N. and Leathers, K., 2009. Community autoethnography: Compiling the personal and resituating whiteness. Cultural Studies $\Leftrightarrow$ Critical Methodologies, 9, 56-83.

Tullis, J., 2013. Self and others: Ethics in autoethnographic research. In: S. Holman Jones, T. Adams and C. Ellis, eds. Handbook of autoethnography. Walnut Creek, CA: Left Coast Press, 244-261 
Turner, I., Short, N., Grant, A and Adams, T., 2018, eds. International perspectives on autoethnographic research and practice. London: Routledge.

Van Maanen, J., 1988. Tales of the field: On writing ethnography. Chicago: University of Chicago Press.

Whitinui, P., 2014. Indigenous autoethnography: Exploring, engaging and experiencing 'self' as a narrative method of inquiry. Journal of Contemporary Ethnography, 43, 456-487.

Winkler, I., 2018. Doing autoethnography: Facing challenges, taking choices, accepting responsibilities. Qualitative Inquiry, 24, 236-247.

Zehntner, C. and McMahon, J., 2014. Mentoring in coaching: The means of correct training? An autoethnographic exploration of one Australian swimming coach's experience. Qualitative Research in Sport, Exercise and Health, 6, 596-616. 